\title{
Intradiscal Electrothermal Therapy: A Preliminary Report
}

\author{
Vijay Singh, MD
}

Internal disc disruption is a common cause of disabling low back pain in a substantial number of young, healthy adults. A clinical diagnosis of internal disruption, in absence of objective clinical findings, is convincingly established only by means of provocation discography. Intradiscal electrothermal therapy has been shown to be effective in managing chronic disabling discogenic pain.

This prospective pilot outcome study was designed to investigate the effectiveness of intradiscal electrothermal annuloplasty in a series of patients with chronic functionally disabling discogenic low back pain. The results showed greater than $50 \%$ pain relief in $67 \%$ of the patients. In addition, a significant decrease in visual analog pain scores was also seen. Further, the assessment of functional status showed significant improvement with standing and walking, whereas sitting also demonstrated significant improvement in $62 \%$ of the patients, though it was not statistically significant. No complications were noted in the perioperative period or during the follow-up period.

In conclusion, intradiscal electrothermal therapy is a safe and effective procedure in patients suffering with chronic functionally limiting discogenic pain who fail to respond to aggressive conservative modalities of treatments as well as interventional therapy with injections.

Keywords: Intradiscal electrothermal therapy, chronic low back pain, internal disc disruption, discogenic pain, and discography
The costs for low back pain, including disability and litigation, are estimated to be more than $\$ 100$ billion a year $(1,2)$. Low back pain is the second most common reason people seek health care. At some point in life, pain of spinal origin will affect $80 \%$ of the population; $35 \%$ to $79 \%$ of those may end up suffering from chronic back pain (1-3). Low back pain and pain that originates from disc disease can be especially difficult to diagnose and treat $(1,3-10)$. Several clinical studies have suggested that as few as $1 \%$ to $30 \%$ of low back problems can be attributed to nerve-root compression (4-6). The symptoms of back pain (with or without referred pain) without neurological symptomology strongly suggest a somatic origin within the musculoskeletal tissues of the lumbar spine (4). Computed tomography (CT), myelography and magnetic resonance imaging (MRI) may help to determine if there is an obvious disc injury; however, none of these will rule out internal disc disruption with certainty. Crock (10) reported a condition that is characterized by internal disruption of the disc, discogenic lumbar pain in

From Pain Diagnostics Associates, Niagara, Wisconsin. Dr. Singh is medical director of Pain Diagnostics Associates. Address correspondence: Vijay Singh, MD, Pain Diagnostics Associates, 1601 Roosevelt Road, Niagara, WI 54151 the absence of disc abnormality, absence of nerve-root compression, and no abnormality seen with CT, or myelography. Sachs and colleagues (11) and Vanharanta and coworkers (12) reported strong correlations between outer annulus disruption and pain reproduction on discography. According to their results, more than $70 \%$ of fissures reaching the outer third of the annulus were associated closely with pain reproduction. Thus, the intervertebral disc is felt to be a common source of chronic low back pain by many investigators $(6,13-15)$. In fact, Schwarzer and colleagues (15) estimated the prevalence of discogenic pain among patients with chronic low back pain to be 39\%. Thus, a discogenic etiology of low back pain exists in a subgroup of patients suffering with chronic low back pain $(6,16,17)$. Nonoperative measures frequently are unable to reduce their pain and improve the functional status $(5,16-19)$. In addition, surgical treatment of these patients, including interbody fusion techniques, has yielded only mixed results (19-26). Saal and Saal (16) and Derby and coworkers (17) reported significant improvement in functional outcome in patients with chronic discogenic low back pain treated thermally by intradiscal catheter. With this technique, thermal therapy is targeted to the annulus of the disc using a navigable intradiscal catheter at a temperature range that both modulates the collagen properties of the disc and destroys nociceptive nerve endings (17). 
This article reports on a clinical prospective study designed to determine the outcome in a group of patients with chronic low back pain who failed to respond to conservative and invasive modalities of treatments in a ru$\mathrm{ral} /$ private practice setting.

\section{METHODS}

From June 1, 1999, thru August 31, 1999, 23 consecutive patients undergoing the intradiscal electrothermal therapy procedure were enrolled into a prospective pilot outcome study. Clinical inclusion criteria were back pain greater than 6 months; lack of response to conservative treatment; normal neurologic examination; absence of nerve-root tension signs; absence of compressive lesion on MRI; concordant pain reproduction of typical symptoms with provocative discography at one or more levels; and intensity of the pain limiting the function. Exclusion criteria included inflammatory arthritis, nonspinal conditions that could mimic lumbar pain, and medical disorders that would preclude appropriate follow-up evaluation and participation.

All 23 patients who met the inclusion criteria were evaluated by multiple physicians and underwent various types of conservative modalities of treatments including nonsteroidal anti-inflammatory agents, opiates, physical therapy, and fluoroscopically directed epidural injections. There were no exclusions in enrollment.

The intradiscal electrothermal therapy procedure was performed at up to two symptomatic levels utilizing a navigable intradiscal catheter with a thermal-resistive coil that raises disc temperatures in the posterior annular wall in order to modify collagen and coagulate nociceptors. Using standard discography technique, under conscious sedation, an ORATEC ${ }^{\circledR}$ Interventions $30-\mathrm{cm}$ SpineCATH $^{\mathrm{TM}}$ (Oratec Interventions, Inc, Menlo Park, CA), with a 6-cm active electrothermal tip is inserted into the annulus or nucleus by a 17-gauge introducer. Following catheter positioning, electrothermal heat is generated along the active portion of the catheter. Our heating protocol included 16.5 minutes in automode, with the final temperature reached being 80 to 90 degrees. A single heating treatment was administered at each level. After heating, antibiotic was administered intradiscally for prophylaxis against disc infection.

All patients were followed postprocedure at 1, 2, 3, and 6 months. The patients also underwent appropriate rehabilitation.

\section{Table 1. Patient Characteristics}

\begin{tabular}{|c|c|c|c|c|}
\hline & & Male & Female & Total \\
\hline \multicolumn{2}{|l|}{ Number } & 9 & 12 & 21 \\
\hline \multirow[t]{2}{*}{ Age (years) } & $\begin{array}{l}\text { Mean } \\
\pm \text { SEM }\end{array}$ & $\begin{array}{c}44.2 \\
\pm 3.53\end{array}$ & $\begin{array}{c}44.8 \\
\pm 2.29\end{array}$ & $\begin{array}{c}44.6 \\
\pm 1.95\end{array}$ \\
\hline & Range & 24 to 60 & 32 to 59 & 24 to 60 \\
\hline \multirow{2}{*}{$\begin{array}{l}\text { Duration of } \\
\text { pain in months }\end{array}$} & $\begin{array}{l}\text { Mean } \\
\pm \text { SEM }\end{array}$ & $\begin{array}{c}104.2 \\
\pm 49.89\end{array}$ & $\begin{array}{c}82.7 \\
+33.94\end{array}$ & $\begin{aligned} & 91.9 \\
+ & 28.18\end{aligned}$ \\
\hline & Range & 6 to 372 & 6 to 384 & 6 to 384 \\
\hline \multirow{2}{*}{$\begin{array}{l}\text { No. of levels } \\
\text { treated }\end{array}$} & Single & 1 & 8 & 9 \\
\hline & Multiple & 5 & 7 & 12 \\
\hline
\end{tabular}

Data were gathered using customized data-recording sheets. Data were collected at baseline, as well as at each follow-up. All data were recorded numerically and subsequently analyzed. Paired tests were for pre-and postprocedure visual analog scale (VAS) scores for pain and functional status; $P$ values less than 0.05 were considered significant.

\section{RESULTS}

A total of 23 patients underwent the intradiscal electrothermal therapy procedure from June 1, 1999, to August 31,1999 . Of the 23 patients, follow-up data were recorded for 21 at various intervals. Follow-up information was not available on two patients, as one patient died due to a cardiovascular event approximately 5 months postprocedure and one patient moved out of the area without a forwarding address. The one patient who died due to a cardiovascular event reported $100 \%$ relief at her 4 month follow-up visit. However, she was not included in

Table 2. Analysis of pain relief achieved with evaluation of visual analogue scales of pain

\begin{tabular}{|c|c|c|c|c|}
\hline & Pre & Post & Difference & P Value \\
\hline Current & $\begin{array}{c}6.24 \\
\pm 0.46\end{array}$ & $\begin{array}{r}3.90 \\
\pm 0.70\end{array}$ & $\begin{array}{r}2.33 \\
\pm 0.50\end{array}$ & 0.000 \\
\hline Best & $\begin{array}{c}3.52 \\
\pm 0.38\end{array}$ & $\begin{array}{c}2.00 \\
\pm 0.47\end{array}$ & $\begin{array}{c}1.52 \\
\pm 0.38\end{array}$ & 0.001 \\
\hline Worst & $\begin{array}{c}8.38 \\
\pm 0.37\end{array}$ & $\begin{array}{c}5.71 \\
\pm 0.74\end{array}$ & $\begin{array}{r}2.67 \\
\pm 0.57\end{array}$ & 0.000 \\
\hline
\end{tabular}

Values are Mean \pm standard error for mean 
Table 3. Analysis of overall pain relief follow intradiscal electrothermal therapy

\begin{tabular}{ll}
\hline$\%$ of pain relief & Proportion of patients \\
\hline$<50$ & $33 \%(7)$ \\
$50-74$ & $10 \%(2)$ \\
$>75$ & $57 \%(12)$ \\
\hline
\end{tabular}

the statistical analysis.

\section{Patient Characteristics}

There were 21 patients, 9 men and 12 women, (Table 1), ages ranging from 24 to 60 years, with a duration of pain ranging from 6 to 384 months. Nine patients underwent electrothermal therapy at one level and 12 patients underwent multiple levels. Of the 21 patients seen, 9 were working and 12 were not working. Four of those patients reported that they could not work due to their pain. Of those four, one patient was receiving long-term disability and Workers' Compensation, one was receiving Workers' Compensation, and the other two were not receiving either Workers' Compensation or long-term disability. The remaining eight were not working for reasons unrelated to functional limitations secondary to low back pain. Among the nine patients working, one patient was receiving Workers' Compensation; however, this patient continued to work on a limited basis prior to the procedure. None of the patients were involved in litigation, and 17 of 21 patients were using narcotic analgesics for pain control.

\section{Pain Relief}

All of the patients reported significant pain relief follow- ing the intradiscal electrothermal therapy procedure, (Table 2). Visual analog scores were analyzed using current scores, best scores, and worst scores. Statistically significant difference was noted with all pain scales, with a $P$ value of 0.000 for current VAS, 0.001 for best VAS, and 0.000 for worst VAS.

The pain relief was also analyzed using patient perceptions: relief less than $50 \%, 50 \%$ to $74 \%$, and $75 \%$ or greater relief. Seven patients, or 33\%, reported pain relief less than 50\%; whereas 14 patients, or $67 \%$, reported relief greater than $50 \%$; with $57 \%$, or 12 patients, reporting relief of $75 \%$ or greater (Table 3 ).

Narcotic use also decreased by $29 \%$. However, this failed to achieve statistical significance $(P=0.063)$.

\section{Functional Status}

Functional status was evaluated by means of tolerance to sitting, standing, and walking (Table 4). Prior to the intradiscal electrothermal therapy procedure, $33 \%$ of the patients were able to sit for more than 30 minutes, 29\% were able to stand for more than 30 minutes, and 19\% were able to walk for more than 30 minutes. Following the intradiscal electrothermal therapy procedure, sitting, standing and walking tolerance improved. However, statistically significant differences were noted only with standing and walking; whereas, even though sitting capacity improved to greater than 30 minutes in $57 \%$ of the patients, from $33 \%$, it was statistically not significant.

Gross evaluation of change in functional status following the intradiscal electrothermal therapy procedure (Table 5) showed improvement in $62 \%$ of patients in terms of sitting and standing, whereas it was seen in $71 \%$ of the patients with walking.

Table 4. Analysis of change of functional status following intradiscal electrothermal therapy procedure

\begin{tabular}{llllclc}
\hline \multirow{2}{*}{ Tolerance(Minutes) } & \multicolumn{2}{c}{ Sitting } & \multicolumn{2}{c}{ Standing } & \multicolumn{2}{c}{ Walking } \\
\cline { 2 - 7 } & Pre & Post & Pre & Post & Pre & Post \\
\hline $1-30$ & $67 \%(14)$ & $43 \%(9)$ & $71 \%(15)$ & $38 \%(8)$ & $81 \%(17)$ & $38 \%(8)$ \\
$30-60$ & $33 \%(7)$ & $14 \%(3)$ & $24 \%(5)$ & $19 \%(4)$ & $19 \%(4)$ & $19 \%(4)$ \\
$>60$ & 0 & $43 \%(9)$ & $5 \%(1)$ & $43 \%(9)$ & 0 & $43 \%(9)$ \\
$P$ Value & & 0.1211 & & 0.0299 & 0.0046 \\
\hline
\end{tabular}


Table 5. Change in functional status following intradiscal electrothermal therapy procedure

\begin{tabular}{llll}
\multicolumn{3}{c}{ the rapy procedure } \\
\hline Outcome & Sitting & Standing & Walking \\
\hline Decreased & $24 \%(5)$ & $10 \%(2)$ & $5 \%(1)$ \\
No change & $14 \%(3)$ & $28 \%(6)$ & $24 \%(5)$ \\
Improved & $62 \%(13)$ & $62 \%(13)$ & $71 \%(15)$ \\
\hline
\end{tabular}

\section{DISCUSSION}

The intervertebral disc is composed of two distinct parts, the annulus fibrosus and the nucleus pulposus. The matrix of the nucleus pulposus is rich in proteoglycans, whereas the annulus fibrosus is comprised predominantly of collagenous tissue. The third component of the disc is vertebral endplate comprised of two cartilaginous layers that line the top and bottom of each disc and separate it from the vertebral bodies. The annulus has two distinct layers: the outer annulus, which is composed of Type I collagen (as is found in tendon) and the inner annulus, which is composed of Type II collagen (as in hyaline cartilage). The collagen fibers are arranged in sheets called lamellae.

The nucleus pulposus is $70 \%$ to $90 \%$ water, makes up two thirds of the surface area of the disc and is responsible for bearing $72 \%$ of the compressive load borne by the disc. The nucleus's proteoglycan matrix is responsible for this support. Proteoglycan units are made up of several proteoglycans linked to a polypeptide chain. Proteoglycan aggregates are made up of several proteoglycan units bound to a hyaluronic acid that is stabilized by a small mass of protein known as the link protein. They can absorb enough water to increase their weight by approximately $250 \%$. Proteoglycans are synthesized by chondrocytes within the nucleus and are slowly turned over by the low-grade metabolic process of the disc. They are localized to the matrix of the nucleus and may be capable of inciting an inflammatory response when exposed to mucosal surfaces.

The pathophysiology of chronic low back pain in general and chronic discogenic pain in particular is complex. The disc is a nociceptively innervated structure capable of pain generation $(6,13,27-35)$. Multiple investigators have shown that granulation tissue and ingrowth of small unmyelinated neural fibers occur in degenerative and dis- rupted discs (13). Increased shear stress across the annular wall can lead to pain generation by mechanical stimulation of annular nociceptors $(6,13,27,36-41)$; nociceptors exposed to inflammatory substances have been shown to sustain a lower threshold of firing (42-46); and chronic discogenic pain may result from mechanical stimulation of annular fissures, or from delamination, in which annular lamellae repetitively stimulate nociceptors that may have been presensitized by the intradiscal biochemical milieu, including phospholipase $\mathrm{A}_{2}\left(\mathrm{PLA}_{2}\right)$ (47), nitrous oxide (48), a lowered $\mathrm{pH}$ (42), or metalloprotinase activity (16).

The current study was designed to determine the outcome in a group of patients with functionally limiting chronic low back pain who failed to respond to conservative and invasive modalities of treatments. The only treatment left for these individuals was interbody fusion surgery. However, interbody fusion surgery yielded mixed results, with a $40 \%$ to $90 \%$ success rate $(16,17,22-26)$. The intradiscal catheter thermal therapy has been shown to yield impressive preliminary results $(16,17)$. The patients in this study group suffered with chronic disabling pain an average of 6 to 7.5 years. They also failed to respond to all aggressive modalities of treatments except surgery. Following the intradiscal thermal treatment, a significant proportion of these patients achieved clinical, meaningful and statistically significant improvement in pain and functional level.

Even though the follow-up period in this study may be criticized for being too short for assessing the efficiency of a major spinal procedure, the length of the follow-up period is appropriate for this type of therapy. Intradiscal therapy is associated with minimal morbidity, even though considered invasive, and it is much less invasive than surgical interventions such as interbody fusion. In addition, Saal and Saal (16) also showed that there was no statistical difference between patient outcomes assessed at 6 months and those evaluated at longer follow-up intervals, which essentially suggested that there is no deterioration in improvement between 6 months and 12 months, which is also confirmed by our personal experience. Further, the short-term morbidity of the intradiscal thermal procedure is extremely minimal; and, consequently, the long-term complications are also minimal, and none have been reported. No complications were observed in the 23 patients included in this study.

Further criticism may be directed at the lack of present evidence with regards to the long-term effect of intradiscal 
therapy on the disc. However, degenerative discs have been shown to have a natural history of progression (36, $37,39)$. Hence, one can assume that it is unlikely that the long-term effect produced by thermal treatment of the disc at the temperatures used in this study would harm the treated segment beyond the known consequences of the degenerative cascade (16). This is in contrast to documented short- as well as long-term negative consequences of fusion surgery $(16,17,22-26)$.

Finally, criticism may be directed at the nonrandomized nature of the study. However, once again, the issues of ethics, feasibility, cost, and reliability pose challenges to the randomized trial, which theoretically represents the "gold standard" (49-56). In a recent analysis, Concato et al (57) analyzed five clinical topics in 99 reports, which included both randomized studies as well as observational studies. The results of this analysis (57) showed that the well-designed observational studies (with either a cohort or a case-control design) do not systematically overestimate the magnitude of the effects of treatments as compared with those in randomized, controlled trials on the same topic. This essentially challenged the current consensus about the hierarchy of study designs in clinical research. However, this is not to say that we do not need randomized, controlled studies, as Pocock and Elbourne (58) observed: a systematic review of evidence on a therapeutic topic needs to take into account the quality of the evidence, as these authors stated; any study, randomized or observational, may have flaws in design or analysis.

\section{CONCLUSION}

Based on the results of the present study, it is concluded that intradiscal thermal therapy is a safe and effective procedure in patients suffering with chronic functionally limiting pain with positive discs who fail to respond to aggressive conservative modalities of treatment, as well as interventional management with fluoroscopically directed epidural injections. This appears to be a promising, minimally invasive treatment for chronic discogenic low back pain, which also appears to be cost effective. However, issues requiring further clarification include exact mechanism of action, reasons for failures, optimal treatment parameters, long-term results and possibility of disc deterioration beyond the natural progression of disc degeneration. Finally, considering the only option available for these patients, namely interbody fusion, results of this study and other studies (16-17), justify its continued use while awaiting further studies, specifically, controlled, prospective, randomized ones.

\section{REFERENCES}

1. Manchikanti L, Singh V, Bakhit CE et al. Interventional techniques in the management of chronic pain: Part 1.0. Pain Physician 2000; 3:7-42.

2. Walker BF. The prevalence of low back pain: A systematic review of the literature from 1966 to 1998 . J Spinal Disord 2000; 13:205-217.

3. Manchikanti L. Epidemiology of low back pain. Pain Physician 2000; 3:167-192.

4. Ito M, Incorvaia KM, Yu SF et al. Predictive signs of discogenic lumbar pain on magnetic resonance imaging with discography correlation. Spine 1998; 23:1252-1260.

5. Derby R, Howard MW, Grant JM et al. The ability of pressure controlled discography to predict surgical and nonsurgical outcomes. Spine 1999; 24:364-372.

6. Sehgal N, Fortin JD. Internal disc disruption and low back pain. Pain Physician 2000; 3:143-157.

7. Deyo RA, Tsui-Wu JY. Descriptive epidemiology of low-back pain and its related medical care in the United States. Spine 1987; 12:264-268.

8. Mooney V. Where is the pain coming from? Spine 1987; 12:754-759.

9. Nachemson AL. The lumbar spine. An orthopaedic challenge. Spine 1976; 1:59-71.

10. Crock HV. Internal disc disruption: A challenge to disc prolapse fifty years on. Spine 1986; 11:650-653.

11. Sachs BL, Vanharanta H, Spivey, MA et al. Dallas discogram description: A new classificiation of CT/ discography in low back disorders. Spine 1996; 21:7986.

12. Vanharanta H, Sachs BH, Ohnimeiss DD et al. Pain provocation and disc deterioration by age: A CT/discography study in a low back pain population. Spine 1989; 14:420-423.

13. Coppes M, Marani E, Thomeer R et al. Innervation of 'painful' lumbar discs. Spine 1997; 22:2342-2350.

14. Kuslich SD, Ulstrom CL, Michael CJ. The tissue origin of low back pain and sciatica: A report of pain response to tissue stimulation during operations on the lumbar spine using local anesthesia. Orthop Clin North Am 1991; 22:181-187.

15. Schwarzer A, April C, Derby R et al. The relative contributions of the disc and zygapophyseal joint in low back pain. Spine 1994; 19:801-806.

16. Saal JS, Saal JA. Management of chronic discogenic low back pain with a thermal intradiscal catheter. Spine 2000; 25:382-388.

17. Derby R, Eek B, Chen Y et al. Intradiscal electrothermal annuloplasty (IDET): A novel approach for treating chronic discogenic back pain. Neuromodulation 2000; 3:82-88.

18. Rhyne AL, Smith SE, Wood KE et al. Outcome of unoperated discogram-positive low back pain. Spine 
1995; 20:1997-2000.

19. Zdeblick TA. A prospective, randomized study of lumbar fusions: Preliminary results. Spine 1993; 18:983991.

20. Wetzel FT, LaRocca SH, Lowery GL et al. The treatment of lumbar spinal pain syndrome diagnosed by discography: Lumbar arthrodesis. Spine 1994; 19:792800 .

21. Vamvanij V, Fredrickson B, Thorpe JM et al. Surgical treatment of internal disc disruption: An outcome study of four fusion techniques. J Spinal Disord 1998; 11:375-382.

22. Gill K, Blumenthal S. Functional results after anterior lumbar fusion at L5-S1 in patients with normal and abnormal MRI scans. Spine 1992; 17:940-942.

23. Greenough CG, Peterson MD, Hadlow S et al. Instrumented posterolateral lumbar fusion. Results and comparison with anterior interbody fusion. Spine 1998; 23:479-486.

24. Knox B, Chapman T. Anterior lumbar interbody fusion for discogram concordant pain. J Spinal Disord 1993; 6:242-244.

25. Newman M, Grinstead G. Anterior lumbar interbody fusion for internal disc disruption. Spine 1992; 17:831833.

26. Parker L, Murrell S, Boden S et al. The outcome of posterolateral fusion in highly selected patients with discogenic low back pain. Spine 1996; 21:1835-1838.

27. Bogduk N, Tynan W, Wilson AS. The nerve supply to the human lumbar intervertebral disc. J Anat 1981; 132:39-56.

28. Roofe PG. Innervation of the annulus fibrosus and posterior longitudinal ligament. Arch Neurol Psychiatry 1940; 44:100-103.

29. Malinsky J. The ontogenetic development of nerve terminations in the intervertebral discs of man. Acta Anat 1959; 38: 96-113.

30. Groen GJ, Balijet B, Drukker J. Nerves and nerve plexuses of the human vertebral column. Am J Anat 1990; 188:282-296.

31. Nakamura S, Takahashi K, Takahashi Y et al. Origin of nerves supplying the posterior portion of lumbar intervertebral discs in rats. Spine 1996; 21:917-924.

32. Yamashita T, Minaki Y, Oota I et al. Mechanosensitive afferent units in the lumbar intervertebral disc and adjacent muscle. Spine 1993; 18: 2252-2256.

33. Yoshizawa H, O'Brien JP, Thomas Smith W et al. The neuropathology of intervertebral discs removed for low back pain. J Pathol 1980; 132:95-104.

34. Morinaga T, Takahashi K, Yamagata M et al. Sensory innervation to the anterior portion of lumbar intervertebral disc. Spine 1996; 21: 1848-1851.

35. Bogduk N, Long D. The anatomy of the so-called "articular nerves" and their relationship to facet denervation in the treatment of low back pain. $J$
Neurosurg 1979; 51:172-177.

36. Adams MA, Dolan P, Hutton WC. The stages of disc degeneration as revealed by discograms. J Bone Joint Surg 1986; 68:36-41.

37. Ito S, Yamada Y, Tsuboi. An observation of ruptured annulus fibrosis in lumbar discs. J Spine Disord 1990; 4:462-466.

38. Kauppila LI. Ingrowth of blood vessels in disc degeneration: Angiographic and histological studies of cadaver spines. J Bone Joint Surg 1995; 77:26-31.

39. Osti O, Vernon-Roberts B, Moore R et al. Anular tears and disc degeneration in the lumbar spine: A postmortem study of 135 discs. J Bone Joint Surg 1992; 74:678-682.

40. Ashton IH, Walsh DA, Polak JH et al. Substance P in intervertebral discs: Binding sites on vascular endothelium of the human annulus fibrosus. Acta Orthop Scand 1994; 65:635-639.

41. Galante JO. Tensile properties of human annulus fibrosus. Acta Orthop Scand 1967; 100(Suppl):1-91.

42. Kitano T, Zerwekh JE, Usui Y et al. Biochemical changes associated with symptomatic human intervertebral disc. Clin Orthop 1993; 293:372-377.

43. Levine JD, Lam D, Taiwo YO, et al. Hyperalgesic properties of 15 lipoxygenase products of arachidonic acid. Proc Natl Aca Sci USA 1986;83:5331-5334.

44. Ozaktay AC, Kallakuri S, Cavanaugh JM. Phospholipase A2 sensitivity of the dorsal root ganglion. Spine 1998; 23:1296-1306.

45. Pateromichelakis S, Rood JP. Prostaglandin E increases mechanically evoked potentials in the peripheral nerve. Experientia 1981; 27:282-284.

46. Wall PD, Gutnick M. Ongoing activity in peripheral nerves: The physiology and pharmacology of impulses originating in a neuroma. Exp Neurol 1974; 43:580593.

47. Franson R, Saal JS, Saal JA. Human disc phospholipase A2 is inflammatory. Spine 1992; 17(Suppl):S190192.

48. Kang JD, Georgescu HI, McIntyre L et al. Herniated lumbar intervertebral discs spontaneously produce matrix metalloproteinases, nitric oxide, interleukin6, and prostaglandin E2. Spine 1996, 21:271-277.

49. Van Tulder MW, Koes BW, Bouter LM. Conservative treatment of acute chronic nonspecific low back pain. A systematic review of randomized controlled trials of the most common interventions. Spine 1997; 22:2128-2156.

50. Bigos SJ, Boyer OR, Braen GR et al. Acute Low Back Problems in Adults. Clinical Practice Guideline Number 4. AHCPR Publication No. 95-0642. Rockville, MD, Agency for Health Care Policy and Research, Public Health Service, US Department of Health and Human Services, December 1994.

51. Turner JA, Loeser JD, Bell KG. Spinal cord stimulation for chronic low back pain. A systematic litera- 
ture synthesis. Neurosurgery 1995; 37:1088-1098.

52. Weinstein JN. The tortoise and the hare. Is there a place in spine surgery for randomized trials? Spine 1999; 23:2548-2549.

53. Winter RB. The prospective, randomized, controlled clinical trial in spine surgery. Fact or fiction? Spine 1999; 23:2550-2552.

54. Carey TS. Randomized controlled trials in surgery. An essential component of scientific progress. Spine 1999; 23:2553-2555.

55. Fairbank J. Randomized controlled trials in the sur- gical management of spinal problems. Spine 1999; 23:2556-2563.

56. Tosteson TD. Point of view. Spine 1999; 24:25622563.

57. Concato J, Shah N, Horwitz R. Randomized, controlled trials, observational studies, and the hierarchy of research designs. N Engl J Med 2000; 342:18871892.

58. Pocock S, Elbourne D. Randomized trials or observational tribulations? (editorial). N Engl J Med 2000; 342:1907-1909. 